\title{
A review on recent advances in chitosan applications
}

\author{
Ayesha Bibi ${ }^{1 *}$, Mareena Ibrar $^{2}$, Abdullah Shalmani ${ }^{3}$, Touseef Rehan ${ }^{4}$ \\ and Quratulain ${ }^{5}$ \\ 1. Department of Biotechnology, Women University Mardan, KP-Pakistan \\ 2. Department of Microbiology Women University Mardan, KP-Pakistan \\ 3. College of Life Sciences, Northwest A\&F University-China \\ 4. Department of Biotechnology Quaid e Azam University Islamabad-Pakistan \\ 5. Department of Zoology, Women University Mardan-Pakistan \\ *Corresponding author's email: ayeshabb2009@yahoo.com \\ Citation \\ Ayesha Bibi, Mareena Ibrar, Abdullah Shalmani, Touseef Rehan and Quratulain. A review on recent advances in \\ chitosan applications. Pure and Applied Biology. Vol. 10, Issue 4, pp1217-1229. \\ http://dx.doi.org/10.19045/bspab.2021.100128
}

\begin{tabular}{llll}
\hline \hline Received: 19/11/2020 & Revised: 29/01/2021 & Accepted: 03/02/2021 & Online First: 08/02/2021 \\
\hline \hline
\end{tabular}

\section{Abstract}

Chitosan, derivative of chitin is the second most abundant natural polymer and is widely distributed throughout the nature. The numbers of applications of chitosan and their derivatives have been increasing steadily in the last decade. Chitosan has been shown to be a versatile nontoxic material with multiple responses. To date, there is enough evidence indicating that after chitosan application plants can acquire enhanced tolerance to a wide variety of pathogenic microorganisms. A high antimicrobial activity was observed by chitosan against bacteria, viruses, fungi, nematodes and insects. Chitosan can be a cost-effective way to protect crops from microbial pathogens and inhibit development of resistant pathogens. It can assist in the goal of sustainable agriculture in unfavorable climatic conditions e.g. heat, cold, salinity, drought stresses and improve growth. Today, chitosan is considered as a bio functional polysaccharide with probably the most notable growth and potential for applications in various fields. The progress in chitin chemistry and the need to replace additives and non-natural polymers with functional natural-based polymers have opened many new opportunities for chitosan and its derivatives. Chitosan is environmentally friendly and which attributes to the rapid development in its applications in industry but since chitosan is insoluble in water, the use of chitosan in a basic environment is limited. This review hopes to enlist the latest applications of chitosan in different fields to help provide easily accessible knowledge for aspiring researchers.

Keywords: Antimicrobial; Chitin; Chitosan; Food; Packaging; Storage

\section{Introduction}

Chitosan is the second abundant biopolymer present on earth after cellulose [1] and is one of the most important carbohydrate biopolymer. Chitosan is derived from deacetylation of chitin that found in the exoskeleton of crustaceans such as shrimps, crab, Ganoderma lucidum, lobster, insect, mollusks [2] also found in fungal cell wall, amoebae, chrysophytes algae, yeast and some fungi cell wall. Chitosan has many application [3] and is one of the natural multifunctional polymers due to its unique and versatile biological properties and is therefore regarded as a useful compound in medical and pharmaceutical technology [4]. It contains amino groups with high nitrogen content and has vast applications in medicine, environment, food sector, agricultural 
settings, makeup industry, papermaking and water treatment due to its high biocompatibility, biodegradability, and low or no toxicity along with antimicrobial properties [5]. The main sources of chitosan production for commercial applications are marine crustaceans (mainly shrimps). Chitosan is isolated from marine shell waste for industrial use by using different chemical methods including treatment of chitin with hydroxides at high temperature usually on $80^{\circ} \mathrm{C}$. Crustaceans exoskeleton is first acid demineralized which removes mineral and salt (proteins) from liquid then sodium hydroxide is used to remove proteins from demineralized shells. Then deacetylase strong bases are used and eventually chitin yields chitosan. Chitosan can also be produced by enzymatic method (Fig. 1).

Chitosan is a linear polymer of beta-(1-4)linked N-acetyl-2-amino-2-deoxy-Dglucose and 2-amino-2-deoxy-D-glucose subunits. Recently numerous chitosan derivatives have been produced in wake of increasing demand due to their variety of applications [6]. Different types of chitosan are given in (Table 1).

Chitosan has a major role in agriculture due to its ability to control plant diseases. This polymer was shown to have toxicity against fungi by stopping fungal growth and development and is also affective against bacteria, viruses, and other pests. In plants chitosan triggers defense response against microbial infections, including the pathogen-related (PR) proteins, accumulation of phytoalexins, proteinase inhibitors, callus formation, lignin synthesis. Chitosan is utilized as a soil amendment to control Fusarium wilts in many plant species, it also stimulates the activity of beneficial microorganisms in the soil such as Bacillus, rhizobacteria, fluorescent Pseudomonas, mycorrhiza and actinomycetes [7]. Chitosan is an important biopolymer with various applications. Here we take a look at some of the major applications of Chitosan in different fields.
Chitin

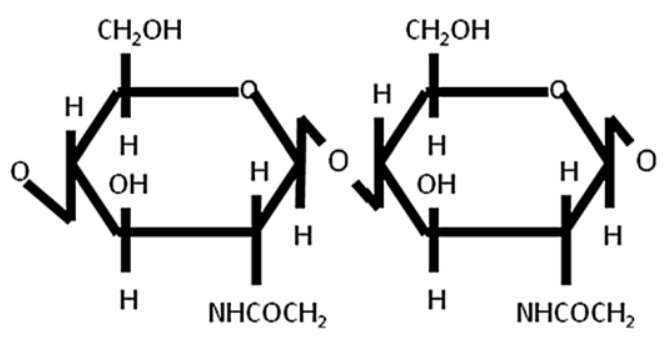

\section{Chitosan}

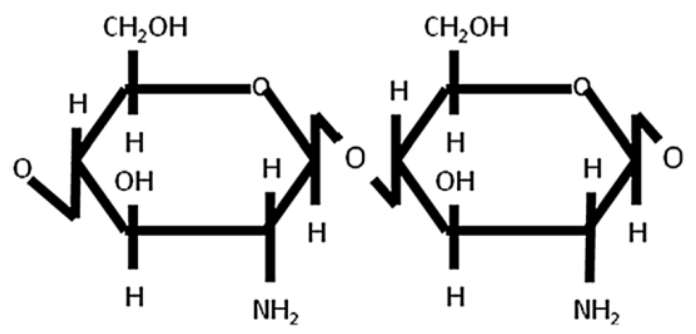

Figure 1. Chemical structure of chitosan

Table 1. Types of Chitosan

\begin{tabular}{|l|l|}
\hline TMC & Trimethyl chitosan \\
\hline CMC & N-carboxymethyl chitosan \\
\hline CMTMC & O-carboxymethyl-N,N,N-trimethyl chitosan \\
\hline
\end{tabular}

\section{Chitosan effect in agriculture}

Chitosan exhibits properties like, antibacterial, antifungal, antiviral and control of diseases through enhancement of innate defenses of plant [1]. Chitosan act as a bio fertilizer and bio fertilizer protestants, improve the production of freesia plant. Chitosan has growth promoting ability, it prevents crop disease [2] reduce the rate of lesions. Chitosan help the uptake of essential nutrients. Nitrogen and phosphorous content was shown to have increased in root and shoots of Eustoma grandiflorum by use of chitosan [3] which consequently has beneficial effect on yield. Carrots when sprayed with chitosan result in decreased incidence of necrotic fungal pathogens and along with growth 
promotion and increased yield in tomato [4].

\section{Plant growth and development}

Chitosan has been established as a natural molecule that elicits numerous biological responses in various plants at different developmental stages. Initially chitosan action was reported in tomato (Solanum lycopersicum $L$ ) and pea (Pisum sativum $L$ ) plants then chitosan was shown to increase defense responses to abiotic and biotic stresses. An initial oxidative burst with hydrogen peroxide $\left(\mathrm{H}_{2} \mathrm{O}_{2}\right)$ accumulation was seen in different plants when supplied with chitosan, it is considered that this can lead to the induction of plant defense enzymes and to the synthesis of secondary metabolites such as lignin, polyphenolics, flavonoids and phytoalexins as noted in many plant species treated with chitosan. Other biochemical and molecular changes observed in plant growth with addition of chitosan include: activation of MAPkinases, callose apposition, increases in cytosolic $\mathrm{Ca}_{2}^{+}$, inhibition of plasma membrane $\mathrm{H}^{+}$-ATPase, chromatin alterations, alkaloids syntheses and phytoregulators (Jasmonic acid, JA, and abscisic acid, ABA) [5].

Some researchers studied the growth and productivity of the sour orange rootstock under drought conditions. Application of the foliar spray of chitosan has been shown to stimulate the growth of sour orange and improved yield and quality of several fruit and vegetable crops [6]. Various applications of chitosan in different plants are given in (Table 2).

Table 2. Chitosan use in agriculture

\begin{tabular}{|c|c|c|}
\hline Plant & Chitosan application & References \\
\hline Maize & $\begin{array}{c}\text { Increase in the seed germination rate was } \\
\text { observed in both maize hybrids in the } \\
\text { presence of chitosan, }\end{array}$ & {$[7]$} \\
\hline Cucumber, Chili, pumpkin & Increment in the seed germination rate & {$[8]$} \\
\hline $\begin{array}{c}\text { cow pea, black gram, } \\
\text { fenugreek }\end{array}$ & $\begin{array}{c}\text { Enhanced viability and purity of the long } \\
\text { time stored Seeds }\end{array}$ & {$[9]$} \\
\hline
\end{tabular}

\section{Chitosan effects on biotic and abiotic stresses}

Plant crops are exposed to various stresses that cause crop loss, but in many plant they have ability to activate priming related mechanism known as stress imprinting [10]. Unlike animals, plants are sessile and therefore, they have developed sophisticated mechanisms to adapt to various biotic (fungi, bacteria, and insects) and abiotic (wounding, salinity, drought, salt, and cold) stresses.

\section{Effect on biotic stress \\ Effect on fungi}

Tomato is entirely sensitive to diseases and damages due to contamination with spoilage microorganisms, Alternaria, Fusarium, Mucor, Penicillium and Rhizopus are the most common fungi species that can infect tomatoes after harvesting, chitosan has been widely tested as a digestible coating and is also reported to enhance the polymer activity against many fungi that attack and infect tomatoes. Chitosan is vital in controlling fungal infections on cut cherry tomatoes, they form protective coating on tomatoes during storage or marketing [11].

Fusarium oxysporum cause infection in plants, lately chitosan nanoparticles have been used for antifungal activities against Fusarium oxyporum [12].

Neutral or negatively charge cationic chitosan is prepared by introducing 1, 2, 3triazolium and pyridinium into chitosan backbone. This synthesized chitosan was used against three kinds of plant threatening fungal strains and the ant-fungal affect was counted by observing the percentage inhibition of mycelia growth. This derivative bearing 1,2,3-triazolium and pyridinium moieties showed stronger 
antifungal action [13]. Different concentration of chitosan and its effectiveness is shown in (Table 3).

Chitosan has been known to induce defense mechanism in tomato, cucumber and rose shrubs; chitosan stimulates other systems like transduction, cascades and elicitorresponsive genes involved in resistance of plants to infection. Phytoalexin accumulation is triggered by chitosan, resulting in antifungal responses provision of protection from further infection. Spraying with chitosan has been shown to significantly increase the length of inflorescences in Dendrobium missteen and also reduce severity of leaf spot disease, Chitosan enhance phytoalexin production in germinating peanut and in solanaceous plants and legumes [14].

Table 3. Different concentration of chitosan used against fungal diseases

\begin{tabular}{|c|c|c|c|}
\hline Chitosan concentration & Microorganism & Diseases & References \\
\hline $1 \%$ chitosan & C.capsici & $\begin{array}{c}\text { Controlling anthracnose in } \\
\text { chili }\end{array}$ & {$[15]$} \\
\hline 0.1 to $0.5 \%$ chitosan & F.oxysporum & Suppressed wilt disease & {$[16]$} \\
\hline $0.1 \%$ chitosan & Pyricularia & $\begin{array}{c}\text { Suppresion leaf blast of } O . \\
\text { sative }\end{array}$ & {$[17]$} \\
\hline $2 \%$ chitosan & $\begin{array}{c}\text { Fusarium } \\
\text { fujikuroi }\end{array}$ & Rice Bakanae Disease & {$[18]$} \\
\hline
\end{tabular}

\section{Effect}

on

\section{bacteria}

Chitosan can be used as bactericide against many plant pathogenic bacteria. Such bacteria damage plant, reduce crop production and spoil fruits and vegetables. Bacteria are less sensitive to chitosan compared to fungi. Antibacterial activity of chitosan against gram positive and gram negative bacteria is different. It shows high efficiency inhibition effect on gram positive as compared to gram negative bacteria. Due to their cell wall composition, gram negative bacteria is most sensitive to chitosan because of lipo-polysaccharids [19].

Chitosan inhibits the growth of a wide range of bacteria. The minimal growthinhibiting concentrations vary from specie to specie from 10-1,000 ppm. Escherichia coli development and growth is inhibited by quaternary ammonium salts of chitosan especially in acidic media, such as $N$ propyl- $N, \quad N$-dimethylchitosan, $N, \quad N$ trimethylchitosan, and $N$-furfuryl- $N, N$ dimethylchitosan. Likewise several derivatives of chitin and chitosan inhibit $E$. coli, Staphylococcus aureus, some Bacillus species and several fish infecting bacteria [1].

The antibacterial properties of chitosan was assessed against $K$. pneumonia, E. coli, $S$. aureus, $P$. aeruginosa, using different concentrations of chitosan, all the chitosan nanoparticles had high inhibition rates against tested microorganisms [20].

Copper nanoparticle (Cu-NP) synthesis has been receiving attention due to its property and applicability. The synthesis of $\mathrm{Cu}-\mathrm{NP}$ by the addition of the acidic chitosan solution to $\mathrm{CuSO} 4$ solution with constant stirring at $70^{\circ} \mathrm{C}$ for $12 \mathrm{~h}$ results in green synthesis. Addition of chitosan aids the stable formation of nanoparticles.

The synthesized $\mathrm{Cu}$-chitosan nanoparticles exhibit antibacterial activity against gram negative as well as gram positive bacteria. However, their activity is more rigorous against gram negative bacteria which may be due to the difference in cell wall composition [17]. Antibacterial activity of Chitosan against different kinds of bacteria is shown in (Table 4). 
Table 4. Antibacterial activity of chitosan

\begin{tabular}{|c|c|c|}
\hline Chitosan & Microorganism & References \\
\hline Chitosan microsphere & $\begin{array}{c}\text { Inhibit the growth of } \text { E.coli } \text { and } \\
\text { Salmonella }\end{array}$ & {$[15]$} \\
\hline $\begin{array}{c}\text { Chitosan and cu-loaded chitosan } \\
\text { Nps }\end{array}$ & $\begin{array}{c}\text { Killed the Staphylococcus aureus, } \\
\text { salmonella typimurium }\end{array}$ & {$[21]$} \\
\hline Chitosan nanopartical & $\begin{array}{c}\text { Showed greater inhibitory activity } \\
\text { against Klebsiella pneumoniae, } \\
\text { Pseudomonas fluorescens } \text { and Proteus } \\
\text { mirabilis. }\end{array}$ & {$[9]$} \\
\hline Chitosan/protaminenanoparticles & $\begin{array}{c}\text { exhibited lower binding affinity } \\
\text { towards } \text { B. cereus }\end{array}$ & {$[22]$} \\
\hline Copper nanoparticle (Cu-NP) & $\begin{array}{c}\text { exhibited inhibitory activity } \\
\text { towards gram negative, positive bacteria }\end{array}$ & {$[17]$} \\
\hline
\end{tabular}

\section{Effect on nematode}

Chitosan is used in agriculture and horticulture as nemati-static or nemati-cidal compound against plant-parasitic nematodes. The addition of effective amount of chitosan in plants enhances growth and yield with no toxicity to the environment. Many researchers have illustrated several effect of chitin based treatment against plant-parasitic nematodes, especially its impact as a nematicide on the activity of soil enzymes, levels of microorganism populations in the soil and the safe quantity of plants. They have demonstrated that chitin can be used to minimize the proliferation of plant nematodes such as citrus nematode (Tylenchulus semipenetrans), root-knot nematodes ( Meloidogyne incognita and Meloidogyne chitwoodi), lesion nematode ( Pratylenchus vulnus ), sugar beet nematode ( Heterodera schachtii), and soybean cyst nematode ( Heterodera glycines ) in soils. Soil amended with chitin at $1 \%(\mathrm{w} / \mathrm{w})$ showed a moderating effect on root-knot nematode in cotton [23].

Root-knot nematodes, Meloidogyne spp cause high yield losses in most cultivated plants in tropical and subtropical areas, due to this temperate environment these plant need suitable plant parasitic nematodes control especially against Meloidogyne spp. which are usually the most damaging especially against tomato. Root-knot nematodes are also difficult to control due to their wide host range, short generation times, high reproductive rates and endoparasitic nature. Chitosan has been used to control disease or reduce their spread to chelate nutrient and minerals, preventing pathogens from accessing them or to enhance plant innate defenses. High and low molecular weight chitosan used to suppress and control root-knot nematode reduce the egg hatching. Chitosan has been shown to enhance the bio-control efficacy of nematophagous fungi to parasitize nematodes [24].

\section{Effect of virus}

Inhibition of the systemic propagation of viruses and viroids throughout the plant and enhancement of the host's hypersensitive response to infection was shown by chitosan. Level of suppression of viral infections varied with molecular weight of chitosan. With the potato virus, tobacco mosaic, alfalfa mosaic virus, peanut stunt virus and cucumber mosaic virus similar observation were reported [1]. Chitosan activity against plant viruses is due to the capability of the polymer to stimulate the plant immune response. Stunting disease of black pepper (Piper nigrum L.) plants is one of the inhibiting factors on the growth of the plants. This disease is a result of infection from pathogenic virus such as Cucumber mosaic virus (CMV) and Piper yellow mottle virus (PYMoV). Multiple infections of these viruses inhibit plant growth. Chitosan can play an important role in 
reducing disease incidence and severity and stimulate plant growth [25].

\section{Effect on insect}

Nosema spp. is fungi-related protozoa of the phylum Microsporidia, intracellular parasites of the Apis species. The species $N$. apis and $N$. ceranae cause honey bee nosematosis, a lethal disease occurring worldwide and resulting in mass death of bees and bee families at apiaries. Chitosan stimulates protective systems of the honeybee species and also exhibit a pronounced fungi-static effect against Ascosphaera apis. Chitosan triggers the immune system of bees and thus participates in the regulation of its protective reactions. Being a naturally occurring compound, it is completely digested by bees and is not accumulated in the bee-farming products, therefore being completely safe and environmentally friendly [26].

\section{Effect on abiotic stress \\ Effect on heat stress}

Temperature above optimum is considered as heat stress for living organism and one of the environmental change for plants [27]. Heat also promotes the infection associated with fungi like Aspergillus flavus and fusarium, and hence increase the production of mycotoxin [28]. Heat stress effect many plant, cause dangerous diseases and reduce the production of crop. Dry bean production becomes effected by heat stress being sensitive to heat stress in reproductive phase of growth [29]. Treatment with chitosan could be effective in late sown plant [30].

\section{Effect on drought stress}

The worldwide crop loss is the biggest problem of agriculture is caused by drought stress which affects the productivity by decreasing yield and inhibiting plant growth. Chitosan is a more effective way to improve the amplitude of drought resistance. The existing results from studies show that certain concentration of chitosan can increase the capacity of drought resistance for crops [31].
The water status of plant is returned by the leaf content. Leaf water content of seedlings can be enhanced by chitosan coating and it also helps increase the chlorophyll concentration under drought stress. And thus chitosan can enhance the photosynthetic activity and accumulation of organic matter in wheat seedlings. Under the drought condition, a well-developed root system absorbs more water to keep the moisture stable. Chitosan coating can reduce the inhibition of roots and stem growth under drought stress, which implies chitosan is able to promote development of root system and can enhance the ability of water absorption, and improve drought resistance of wheat seedlings [14].

\section{Effect on salt stress}

Salinity is severe abiotic stress which leads to decrease in crop production, 6\% of world's total land area is salt affected and causes various crop problems [32]. Some plants act as medicinal plant because they can be used in the manufacture of synthetic drugs according to their chemical structure. Rosemary plant (Rosmarinus officinalis L) contains some flavonoids and essential oil in addition to that they also contain antimicrobial compounds and are therefore used in the manufacture of many herbal shampoos and for food flavoring. This plant needs long time for cultivation, effects of salinity may be attributable to osmotic and ionic effects as well as oxidative stress the free radicals induced by salinity disrupt normal metabolism through lipids peroxidation, protein denaturation and nucleic acids using of chitosan at $250 \mathrm{mg} / \mathrm{l}$, showed best result under salinity stress condition on its productivity [33].

Maize is considered one of the most important cereal crop cultivated across the world but in many parts of the world the productivity of maize is limited by some environmental factors such as salt condition. Salt stress affect the plant in two ways, firstly by osmotic effect in which the uptake of water is reduced and the secondly its effect ion toxicity. The salt enters transpiration system, injury leaf cells and 
cause reduced cell division. Natural elicitor chitosan is used to trigger positive response increasing resistance toward many pathogens, enhancing the tentativeness of beneficial bioflavonoid in a number of plant varieties [34].

\section{Chitosan used in postharvest technology}

In China the Ginkgo biloba L. is a rare relict native species and also has been considered as a living fossil. Seeds of ginkgo are widely consumed in China by frying and boiling or by adding other food to it because they are nutritionally rich but due to the high respiration rate and metabolic activity after the harvest they continuously ripen and therefore are more susceptible to mildew. Ginkgo seeds are highly susceptible to fungal infection and water loss that is related to a prolonged storage time. Due to these problems an effective preservation techniques are needed to be develop for preservation of ginkgo seeds. To decrease the fruit damage and to maintain their quality, chitosan was used along with the application of essential oils, 5 1-methylcyclopropene-6 and refrigeration. Chitosan coatings decrease post-harvest transpiration which is considered the main factor that causes spoilage [35].

Edible coatings provide a promising approach for extending the shelf life of organic products. Edible coatings protect products from mechanical and microbial damage, inhibit deterioration and prevent the escape of favorable volatiles. They are based on natural, biodegradable and consumable materials and therefore satisfy the environmental concerns and respond to customer demands for safe and healthy food [36].

The composite chitosan-gelatin ( $\mathrm{CH}-\mathrm{GL})$ coating was applied to pepper and its effects on storability and on fruit quality was examined. The composite $\mathrm{CH}-\mathrm{GL}$ coating was associated with a $50 \%$ reduction in microbial decay, significant improvement in fruit texture and extensions of possible cold storage lengthening fruit's shelf life up to 21 days without impairment of the respiration or nutritional content of the fruit [37].

Due the phenol rich composition and antioxidant capacity, global demand for fresh grapes increased. It is difficult to preserve the fresh table grapes without treatment because they deteriorate rapidly due to berry water loss and pathogen growth, fumigation chitosan coating is considered as a simple, healthy and innovative technology, for their effectiveness on postharvest quality extension of detached grapes of Alphanose lavallee cultivar various concentration $0 \%$ $, 0.5 \%, 0.1, \%$ and $2.0 \%$ was tested. At all doses the loss in berry weight, skin rupture force and total phenolics content was significantly reduced by chitosan coating and it also improved visual quality. Chitosan at all concentrations was effective on delaying maturity index and changes in berry color values. Among the applied doses, $1 \%$ chitosan solution was recommended to be applied since higher doses were more effective with similar results on overall quality features of berries [38].

To replace the use of synthetic fungicides, application of chitosan treatment at the pre harvest or postharvest stages has been considered as a suitable alternative treatment. This can help extend storage life, prevent postharvest fruit diseases while maintaining the overall quality of the different fresh commodities. Chitosan application as antimicrobial agent to vegetal tissue has been identified as ideal coating. On the other hand, chitosan coating can be incorporated to other functional natural food additives, which might prevent deterioration of fruit quality and enhance its antimicrobial properties. At present time, consumers demand environmental friendly, natural, high quality and with an extended shelf life food products.

Fragaria chiloensis (L.) Mill commonly known as Chilean strawberry is noted for its good fruit quality characters and an intense aroma, presenting a particular white color 
but during ripening, it exhibits a high softening rate which can negatively impact its postharvest life. Application of methyl jasmonate (MeJA) and chitosan has a positive effect on postharvest quality reducing decay and extending shelf life of Fragaria chiloensis L. Chitosan can be used as complete or partial substitute to chemical fungicides practiced in this crop and others [39].

Loquat (Eriobotrya japonica Lindl) contains essential nutrients and phytochemical such as beta carotene that accrues naturally in plant and provides health benefits therefore this fruit is widely consumed. This fruit goes bad quickly, spoilt by microbes, has short postharvest life, and is sensitive to browning and chilling injury. Cold storage is the postharvest practice applied commercially in loquat fruit, but on long storage period loquat is affected by chilling injury because of sensitivity to low temperature. Chitosan coating combined with cold storage preserve fruit quality, prevent a physiological and biochemical changes that occur during postharvest life and prevent oxidation reactions [40].

Chitosan treatment in the fresh products is safe for the consumer and the environment and chitosan has been approved by the United State Food and Drug Administration (USFDA) as a "Generally Recognized as Safe" (GRAS) food additive [41].

\section{Use as biofilm in food packaging}

In the scientific community and in food industry, film form of chitosan natural biopolymer obtained much interest for their potential to replace toxic and nonbiodegradable materials for packaging and structure material [42]. In hydrochloric acid and acetic acid chitosan has certain solubility by which film forming ability of chitosan is conducted. Chitosan based film have been fabricated by many researchers that involve coating, layer-by-layer assembly, casting etc. and the characteristics are also improved such as barrier property, antioxidant activity, antimicrobial activity, mechanical property, indicating capacity, visual appeal and thermal stability. To further extend the applications, fabricated composite films to enlarge the combinational advantages of the obtained chitosan based film other functional material are added. This obtained chitosan based films have been applied to many foods like fruits, vegetables and meat with high quality preservatives expend the potential as an alternative means for food packaging [43] (Table 5).

In food based on their role the chitosan derivatives functions could be different

(1) Facilitate color establishment by stabilizing properties

(2) Antioxidant action and blending

(3) Nutritional fiber resembling elicit helping water retention capacity and fat entrapment

(4) Antimicrobial property, thus imparting health advantage.

Recently patents have been published on chitosan derivatives associated with applications in food engineering [44] through the incorporation of active compounds into packaging materials that are usually used as films or coatings. Active packaging is presently one of the most dynamic technologies used to preserve the quality, safety and sensory properties of food by improvement and preservation of food quality by active packaging that interacts positively with product and environment. Spraying and dipping techniques are used to coat baby carrots. Under Modified Atmosphere Packaging (MAP) conditions the effect of chitosan based coatings increased the quality of baby carrot. Thus the quality of baby carrot is maintained for long storage periods without effecting sensory attributes points out by the application of chitosan. Under MAP conditions the iron based oxygen scavengers in chitosan coating on sliced snack are used. Chitosan coatings was shown to have effective suppression against microbial growth, and the color stability of slice was improved when their coating were used along with oxygen scavengers [45]. 


\section{Table 5. Fabrication of chitosan based films for food packaging application}

\begin{tabular}{|c|c|c|}
\hline 1 & Polymer blends & $\begin{array}{c}\text { Chitosan polymer blends are a good option in the films } \\
\text { fabrication for food packaging because with good tensile } \\
\text { properties and a suitable barrier against the moisture, } \\
\text { gases and water }\end{array}$ \\
\hline 2 & $\begin{array}{c}\text { Incorporation of } \\
\text { bioactive compounds }\end{array}$ & $\begin{array}{c}\text { The polymeric mixture based on chitosan and bioactive } \\
\text { compounds provide a barrier against water vapor and } \\
\text { enhance the tensile properties of the films }\end{array}$ \\
\hline 3 & Nanofillers & $\begin{array}{r}\text { Nanocomposites that include metallic nanoparticles } \\
\text { exhibit an excellent antimicrobial response and good } \\
\text { mechanical and barrier properties. }\end{array}$ \\
\hline 4 & $\begin{array}{c}\text { Mechanical and } \\
\text { barrier properties }\end{array}$ & $\begin{array}{c}\text { The moisture content and yellowness of chitosan-based } \\
\text { films is reduced by incorporating chitosan nanoparticles }\end{array}$ \\
\hline 5 & Antimicrobial activity & $\begin{array}{c}\text { Higher surface area and charge density of chitosan } \\
\text { nanoparticles incorporated in polymer matrix }\end{array}$ \\
\hline
\end{tabular}

\section{Increasing shelf life during storage}

Diseases are developed when the respiration rate of fruit increases [46]. During the mango fruit ripening ethylene is produced. The ethylene production is decreased by the chitosan coating treatment. After 15 days the chitosan coating treatment decreased.

Thomson navel orange was hand-harvested, $0.5 \%, 1 \%$ and $2 \%$ coating were made. Fruit was dipped into the chitosan then dried at environment temperature $\left(12^{\circ} \mathrm{C}\right)$ for $12 \mathrm{~h}$ then fruit was stored for 90 days. During storage, fruit quality properties were measured. Chitosan coating had a beneficial role to maintain the quality and the loss of fruit juice during storage due to higher $\mathrm{pH}$ value. Also, it can be replaced as the suitable edible coating instead of fungicides that are commonly used [47].

Recently many technologies are applied to extend the post-harvest fruit shelf life which includes the cold storage in combination with coating, irradiation and modified atmosphere MAP packaging. Sweet cherry is acceptable by consumers when coated with chitosan because that reduces the most important quality parameters changes [48].

Edible coatings particularly Carnuba wax and chitosan can be used as post-harvest treatment to enhance the storability of bitter gourd fruits under ambient storage conditions [49]. It was observed that refrigerated storage, associated with chitosan coatings, was effective in maintaining postharvest quality of strawberries given that chitosan coatings delayed changes in soluble solids, weight loss, ascorbic acid, total sugars, reducing and non-reducing sugars, treatable acidity, and $\mathrm{pH}$ during 20 days of storage (Table 6). The chitosan concentration of $1.0 \%(\mathrm{w} / \mathrm{v})$ was the most promising in maintaining quality, as well as preserving the fruits for more than 10 days under refrigeration [50].

\section{Action mechanism}

Gram negative bacteria are more susceptible than gram positive bacteria, chitosan show a strong activity against both gram positive and gram negative, even many works determine that there is no difference between the antibacterial activities of chitosan on the bacterial species. The disruption of the cell is caused when chitosan binds to the cell wall of bacteria that is negatively charged which is the most prevalent to change the permeability of membrane, and attachment to their DNA and finally cell death occur subsequently. And the other mechanism that is also related to the chitosan action is chelating agent which bind to the trace metal element and cause microbial growth inhibition by producing toxin [20].

One of the other mechanisms in which the chitosan interfere with the microbial protein present on their surface by which 
intracellular contents escape, have strong antimicrobial activity, this mechanism is effective against various disease causing microbes (pathogens). The electron transport chain is damaged when chitosan chelates trace metal ions. When it enters the cell it disrupts the formation of messenger RNA and their protein cause damage to the cell. And encourage the antibacterial effective action against many strains of salmonella and staphylococcus epidermidias [54].

Table 6. Chitosan increase shelf life during storage

\begin{tabular}{|c|c|c|c|c|}
\hline Chitosan & Storage & Ingredient & Increase shelf life & References \\
\hline coating & $\begin{array}{c}\text { Cold storage at } \\
\text { for 90 days.5c }\end{array}$ & $\begin{array}{c}\text { Xinyu } \\
\text { tangerines }\end{array}$ & $\begin{array}{c}\text { reduce Penicillium decay of } \\
\text { citrus fruit }\end{array}$ & [51] \\
\hline Ag-chitosan & $13 \mathrm{~d}$ at $5{ }^{\circ} \mathrm{C}$ & $\begin{array}{c}\text { The incorporation of } \mathrm{Ag} \\
\text { resulted in mesophilic } \\
\text { melon } \\
\text { reduction } \\
\text { during the latter stages of } \\
\text { storage }\end{array}$ & {$[$ [52] } \\
\hline $\begin{array}{c}\text { combined usage } \\
\text { of chitosan and } \\
\text { rhamnolipid }\end{array}$ & $\begin{array}{c}\text { stored at } 25^{\circ} \mathrm{C} \\
\text { for } 8 \text { weeks }\end{array}$ & $\begin{array}{c}\text { 'Agege Sweet' } \\
\text { orange }\end{array}$ & $\begin{array}{c}\text { Inhibit the growth of } \\
\text { mesophilic bacteria, yeast and } \\
\text { mould }\end{array}$ & {$[$ [53] } \\
\hline
\end{tabular}

\section{Methodology}

The research papers were collected over past 10 years on the subject of application of chitosan polymers against multiple stresses in plants to search the literature. Collected papers thoroughly studied and an outline was designed based on the provided information. Notes were taken for important and relevant points during reading. The review was focused on the topic however it also presents the broad interest. A logical structure was developed to write the review and finally a critical, consistent and up-to date review article was written. Review was shown to field experts in order to get their critical opinion about the manuscript.

\section{Conclusion}

An extensive review was done on the Application of chitosan polymers, as a result of which a paper was written on this topic. This review covered meaningful information about the topic and focus on the antimicrobial properties of chitosan polymers. Insights into this topic provide useful information to upgrade the quality and increase shelf-life of food during storage, packaging.

\section{Future prospects}

- The application of chitosan with other derivatives could be studied.
- The area of subject could be broadened by including other beneficial uses e.g. wound healing

\section{Authors' contributions}

Conceived and designed the experiments: A Bibi, Performed the experiments: M Ibrar, Analyzed the data: A Shalamani, Contributed materials/ analysis/ tools: $\mathrm{T}$ Rehan, Wrote the paper: Q Ain.

\section{References}

1. El Hadrami A, Adam Lr, El Hadrami I \&Daayf F (2010). Chitosan In Plant Protection. Marine Drugs 8(4): 968-987.

2. Nguyen Th, Thi Tv, Nguyen T-T, Le Td, Vo Dmh, Nguyen Dh, Nguyen Ck, Nguyen Dc, Nguyen $\mathrm{Tt}$ \&Bach $\mathrm{Lg}$ (2019). Investigation Of Chitosan Nanoparticles Loaded With Protocatechuic Acid (Pca) For The Resistance Of Pyricularia Oryzae Fungus Against Rice Blast. Polymers 11(1): 177.

3. Al-Gazali L, Bener A, Abdulrazzaq Y, Micallef R, Al-Khayat A \&Gaber $\mathrm{T}$ (1997). Consanguineous Marriages In The United Arab Emirates. J of Biosoc Sci 29(4): 491-497.

4. Ramkissoon A, Francis J, Bowrin V, Ramjegathesh R, Ramsubhag A \&Jayaraman J (2016). Bio-Efficacy Of A Chitosan Based Elicitor On Alternaria Solani And Xanthomonas Vesicatoria 
Infections In Tomato Under Tropical Conditions. Annals of Appl Biol 169(2): 274-283.

5. Malerba M \&Cerana R (2018). Recent Advances Of Chitosan Applications In Plants. Polymers 10(2): 118.

6. Moustafa S \&Abdelzaher H (2018). Increasing Of Tomato Yield Grown In Hydroponic System Using Pythium Oligandrum Isolated From Khoaa, Aljouf, Saudi Arabia. Egyp $J$ of Microbiol 53(1): 1-8.

7. Martins M, Veroneze Júnior V, Carvalho M, Carvalho Dt, Barbosa S, Doriguetto Ac, Magalhães Pc, Ribeiro C, Dos Santos Mh \&De Souza Tc (2018). Physicochemical Characterization Of Chitosan And Its Effects On Early Growth, Cell Cycle And Root Anatomy Of Transgenic And Non-Transgenic Maize Hybrids. Embrapa Milho E Sorgo-Artigo Em Periódico Indexado (Alice).

8. Kashyap Pl, Xiang X \&Heiden P (2015). Chitosan Nanoparticle Based Delivery Systems For Sustainable Agriculture. Inter J of Biol Macromol 77: 36-51.

9. Hipalaswins Wm, Balakumaran $\mathrm{M}$ \&Jagadeeswari S (2016). Synthesis, Characterization And Antibacterial Activity Of Chitosan Nanoparticles And Its Impact On Seed Germination. J Acad Ind Res 5: 65.

10. Jiménez-Arias D, Carrillo-Perdomo E, Gracía-Machado F, Jorge L \&Borges A (2017). Priming Crops To Cope With Stress: Advances In Seed-Priming Approach. Agric Res Updates 15: 1-29.

11. Leandro Dsp, Bitencourt Ta, Saltoratto Al, Seleghim Mh \&Assis Ob (2018). Antifungal Activity Of Chitosan And Its Quaternized Derivative In Gel Form And As An Edible Coating On Cut Cherry Tomatoes. J of Agric Sci (Belgrade) 63(3): 271-285.

12. Dananjaya S, Erandani W, Kim C-H, Nikapitiya C, Lee J \&De Zoysa M (2017). Comparative Study On Antifungal Activities Of Chitosan Nanoparticles And Chitosan Silver Nano Composites Against Fusarium
Oxysporum Species Complex. Inter J of Biol Macromol 105: 478-488.

13. Tan W, Li Q, Dong F, Zhang J, Luan F, Wei L, Chen Y \&Guo Z (2018). Novel Cationic Chitosan Derivative Bearing 1, 2, 3-Triazolium And Pyridinium: Synthesis, Characterization, And Antifungal Property. Carbohydrate Polymers 182: 180-187.

14. Katiyar D, Hemantaranjan A \&Singh B (2015). Chitosan As A Promising Natural Compound To Enhance Potential Physiological Responses In Plant: A Review. Indian $J$ of Plant Physiol 20(1): 1-9.

15. Akter J, Jannat R, Hossain Mm, Ahmed Ju \&Rubayet Mt (2018). Chitosan For Plant Growth Promotion And Disease Suppression Against Anthracnose In Chilli. Intern J of Environ, Agric and Biotechnol 3(3).

16. Oh J-W, Chun Sc \&Chandrasekaran M (2019). Preparation And In Vitro Characterization of Chitosan Nanoparticles And Their BroadSpectrum Antifungal Action Compared To Antibacterial Activities Against Phytopathogens Of Tomato. Agron 9(1): 21.

17. Manikandan A \&Sathiyabama M (2015). Green Synthesis Of Copper-Chitosan Nanoparticles And Study Of Its Antibacterial Activity. $J$ of Nanomedic \& Nanotechnol 6(1): 1.

18. Kim Sw, Park Jk, Lee Ch, Hahn B-S \&Koo Jc (2016). Comparison Of The Antimicrobial Properties Of Chitosan Oligosaccharides (Cos) And Edta Against Fusarium Fujikuroi Causing Rice Bakanae Disease. Curr Microbiol 72(4): 496-502.

19. Xing K, Zhu X, Peng X \&Qin S (2015). Chitosan Antimicrobial And Eliciting Properties For Pest Control In Agriculture: A Review. Agron For Sustainable Devel 35(2): 569-588.

20. Divya K, Vijayan S, George Tk \&Jisha M (2017). Antimicrobial Properties Of Chitosan Nanoparticles: Mode Of Action And Factors Affecting Activity. Fibers And Polymers 18(2): 221-230. 
21. Choudhary Rc, Kumaraswamy R, Kumari S, Pal A, Raliya R, Biswas P \&Saharan V (2017). Synthesis, Characterization, And Application Of Chitosan Nanomaterials Loaded With Zinc And Copper For Plant Growth And Protection, In Nanotechnology, Springer. pp. 227-247.

22. Tamara Fr, Lin C, Mi F-L \&Ho Y-C (2018). Antibacterial Effects Of Chitosan/Cationic Peptide Nanoparticles. Nanomaterials. 8(2): 88.

23. Khalil Ms (2016). Utilization Of Biomaterials As Soil Amendments And Crop Protection Agents In Integrated Nematode Management, In Plant, Soil And Microbes, Springer. pp. 203-224.

24. Vasyukova N, Zinov'eva S, Il'inskaya L, Perekhod E, Chalenko G, Gerasimova N, Il'ina A, Varlamov V \&Ozeretskovskaya O (2001). Modulation Of Plant Resistance To Diseases By WaterSoluble Chitosan. Appl Biochem and Microbiol 37(1): 103-109.

25. Uge E, Sulandari S, Hartono $S$ \&Somowiyarjo S (2018). The Effect Of Chitosan Application Against Plant Growth And Intensity Of Stunting Disease On Black Pepper (Piper Nigrum L.) Seedlings. J Perlindungan Tanaman Indonesia 22(2): 224-232.

26. Saltykova E, Gaifullina L, Kaskinova M, Gataullin A, Matniyazov R, Poskryakov A \&Nikolenko A (2018). Effect Of Chitosan On Development Of Nosema Apis Microsporidia In Honey Bees. Microbiol 87(5): 738-743.

27. Malerba M \&Cerana R (2018). Effect Of Selenium On The Responses Induced By Heat Stress In Plant Cell Cultures. Plants 7(3): 64.

28. Lizárraga-Paulín Eg, Torres-Pacheco I, Moreno-Martínez E \&Miranda-Castro Sp (2011). Chitosan Application In Maize (Zea Mays) To Counteract The Effects Of Abiotic Stress At Seedling Level. Afr J of Biotechnol 10(34): 64396446.

29. Ibrahim Ea \&Ramadan Wa (2015). Effect Of Zinc Foliar Spray Alone And Combined With Humic Acid Or/And Chitosan On Growth, Nutrient Elements
Content And Yield Of Dry Bean (Phaseolus Vulgaris L.) Plants Sown At Different Dates. Scientia Horticul 184: 101-105.

30. Sharif R, Mujtaba M, Ur Rahman M, Shalmani A, Ahmad H, Anwar T, Tianchan D \&Wang X (2018). The Multifunctional Role Of Chitosan In Horticultural Crops; A Review. Mol 23(4): 872.

31. Li Z, Zhang Y, Zhang X, Merewitz E, Peng Y, Ma X, Huang L \&Yan Y (2017). Metabolic Pathways Regulated By Chitosan Contributing To Drought Resistance In White Clover. $J$ of Proteome Res 16(8): 3039-3052.

32. Sen Sk \&Mandal P (2018). Application Of Solid Matrix Priming To Ameliorate Salinity Stress In Mung Bean ('Vigna Radiata'). Austr J of Crop Sci 12(3): 458.

33. Helaly M, Farouk S, Arafa Sa \&Amhimmid $\mathrm{Nb}$ (2018). Inducing Salinity Tolerance Of Rosemary (Rosmarinus Officinalis L.) Plants By Chitosan Or Zeolite Application. Asian J of Adv in Agric Res 1-20.

34. Al-Tawaha Ar, Turk Ma, Al-Tawaha Arm, Alu'datt Mh, Wedyan M, AlRamamneh E \&Hoang At (2018). Using Chitosan To Improve Growth Of Maize Cultivars Under Salinity Conditions. Bulg J Agric Sci 24(3): 437-442.

35. Tian F, Chen W, Fan G, Li T, Kou X, Wu Ce \&Wu Z (2019). Effect Of Ginkgo Biloba Seed Exopleura Extract And Chitosan Coating On The Postharvest Quality Of Ginkgo Seed. J of the Sci of Food and Agric 99(6): 3124-3133.

36. Shiekh Ra, Malik Ma, Al-Thabaiti Sa \&Shiekh Ma (2013). Chitosan As A Novel Edible Coating For Fresh Fruits. Food Sci and Technol Res 19(2): 139155.

37. Ilić Zs, Fallik E, Manojlović M, Kevrešan Ž \&Mastilović J (2018). Postharvest Practices For Organically Grown Products. Contemporary Agric 67(1): 71-80.

38. Sabir Fk, Sabir A, Unal S, Taytak M, Kucukbasmaci A \&Bilgin Of (2019). Postharvest Quality Extension Of Minimally Processed Table Grapes By 
Chitosan Coating. Intern J of Fruit Sci 19(4): 347-358.

39. Saavedra Gm, Figueroa Ne, Poblete La, Cherian S \&Figueroa Cr (2016). Effects Of Preharvest Applications Of Methyl Jasmonate And Chitosan On Postharvest Decay, Quality And Chemical Attributes Of Fragaria Chiloensis Fruit. Food Chem 190: 448-453.

40. Adiletta G, Pasquariello Ms, Zampella L, Mastrobuoni F, Scortichini M \&Petriccione M (2018). Chitosan Coating: A Postharvest Treatment To Delay Oxidative Stress In Loquat Fruits During Cold Storage. Agron 8(4): 54.

41. Romanazzi G, Feliziani E, Baños $\mathrm{Sb}$ \&Sivakumar D (2017). Shelf Life Extension Of Fresh Fruit And Vegetables By Chitosan Treatment. Critical Reviews In Food Sci and Nutr 57(3): 579-601.

42. Priyadarshi R \&Rhim J-W (2020). Chitosan-Based Biodegradable Functional Films For Food Packaging Applications. Innov Food Sci \& Emer Technol 62: 102346.

43. Wang H, Qian J \&Ding F (2018). Emerging Chitosan-Based Films For Food Packaging Applications. J of Agric and Food Chem 66(2): 395-413.

44. Hooda R, Batra B, Kalra V, Rana Js \&Sharma M (2018). Chitosan-Based Nanocomposites In Food Packaging, In Bio-Based Materials For Food Packagingeditors., Springer. pp. 269285.

45. Muxika A, Etxabide A, Uranga J, Guerrero P \&De La Caba K (2017). Chitosan As A Bioactive Polymer: Processing, Properties And Applications. Intern J of Biol Macromol 105: 1358-1368.

46. Silva Gmc, Silva Wb, Medeiros Db, Salvador Ar, Cordeiro Mhm, Da Silva Nm, Santana Db \&Mizobutsi Gp (2017). The Chitosan Affects Severely The Carbon Metabolism In Mango (Mangifera Indica L. Cv. Palmer) Fruit During Storage. Food Chem 237: 372378.
47. Taghinezhad E \&Sharabiani Vr (2018). Effect Of Chitosan Coating On Some Quality Properties Of Thomson Orange During Storage (A Case Study In Iran). Agric Engi Intern: Cigr J 20(1): 157 161.

48. Petriccione M, De Sanctis F, Pasquariello Ms, Mastrobuoni F, Rega P, Scortichini M \&Mencarelli F (2015). The Effect Of Chitosan Coating On The Quality And Nutraceutical Traits Of Sweet Cherry During Postharvest Life. Food and Bioprocess Technol 8(2): 394408.

49. Bhattacharjee D \&Dhua Rs (2017). Impact Of Edible Coatings On Postharvest Behavior Of Bitter Gourd (Momordica Charantia L.) Fruits. Intern J Curr Microbiol Appl Sci 6(3): 336-347.

50. Dos Passos Braga S, Lundgren Ga, Macedo Sa, Tavares Jf, Dos Santos Vieira Wa, Câmara Mps \&De Souza El (2019). Application Of Coatings Formed By Chitosan And Mentha Essential Oils To Control Anthracnose Caused By Colletotrichum Gloesporioides And C. Brevisporum In Papaya (Carica Papaya L.) Fruit. Intern J of Biol Macromol 139: 631-639.

51. Chen C, Nie Z, Wan C \&Chen J (2019). Preservation Of Xinyu Tangerines With An Edible Coating Using Ficus Hirta Vahl. Fruits Extract-Incorporated Chitosan. Biomol 9(2): 46.

52. Ortiz-Duarte G, Pérez-Cabrera Le, Artés-Hernández F \&MartínezHernández Gb (2019). Ag-Chitosan Nanocomposites In Edible Coatings Affect The Quality Of Fresh-Cut Melon. Postharvest Biol and Technol 147: 174184.

53. Adetunji Co, Adejumo Io, Afolabi Is, Adetunji Jb \&Ajisejiri Es (2018). Prolonging The Shelf Life Of 'Agege Sweet'orange With ChitosanRhamnolipid Coating. Hortic, Environ, and Biotechnol 59(5): 687-697.

54. Jamil B, Bokhari H \&Imran M (2017). Mechanism Of Action: How NanoAntimicrobials Act. Current Drug Targets 18(3): 363-373. 